\title{
Quantum Chemical, Molecular Docking, and ADMET Predictions of Ketorolac and its Modified Analogues
}

\author{
Moniruzzaman*1,2, Mohammed Jabedul Hoque ${ }^{3}$, Mohammad Nasir Uddin², Amrin Ahsan² and Tareq Mahmud ${ }^{2}$ \\ ${ }^{1}$ Faculty of Engineering, Department of Applied Chemistry and Biochemical Engineering, Shizuoka University, Japan \\ ${ }^{2}$ Department of Chemistry, University of Chittagong, Bangladesh
}

${ }^{3}$ Faculty of Engineering, Department of Optoelectronics and Nanostructure Science, Shizuoka University, Japan

Received: 制: November 20, 2018; Published: 制: December 05, 2018

*Corresponding author: Moniruzzaman, Faculty of Engineering, Department of Applied Chemistry and Biochemical Engineering,

Shizuoka University, 3-5-1, Johoku, Hamamatsu, 432-8561, Japan

\begin{abstract}
Ketorolac $(\mathrm{K})$ is a non-steroidal agent with potent analgesic and moderate anti-inflammation activity. Adverse health effect and resistant of drugs indicate the importance of the discovery of new potential candidate. Recently, it has been seen the trait of modifying drugs using halogens and alkyl groups play an important role in improving drug performance. All the structures are optimized by employing density functional theory with B3LYP/6-31g (d,p) level theory. Thermal, molecular orbital, electrostatic potential properties have been calculated to investigate their physicochemical properties. From molecular docking, nonbonding interactions, and ADMET calculation it is found that most of the designed structures have better biochemical activity. Finally, this study can be helpful to design a new analgesic agent.
\end{abstract}

Keywords: Drug Design; Ketorolac; Density Functional Theory; HOMO-LUMO; Molecular Docking; ADMET Nonbonding Interactions

Abbreviations: NSAID: Non-Steroidal Anti-Inflammatory Drugs; COX: Cyclooxygenase; HOMO: Highest Occupied Molecular Orbital; LUMO: Lowest Unoccupied Molecular Orbital; DFT: Density Functional Theory; LYP: Lee Yang and Parr; PDB: Protein Data Bank; ADMET: Absorption Distribution Metabolism Excretion and Toxicity; MEP: Molecular Electrostatic Potential; hERG: Human Ether-a-go-go-Related Gene

\section{Introduction}

In computer aided drug design system, molecular docking, nonbonding interactions, and ADMET predictions are important criteria to evaluate newly designed molecules [1]. A group of nonsteroidal anti-inflammatory drugs (NSAIDs) has been routinely medicated for arthritis, fever, and pain through common mechanistic pathways of cyclooxygenase (COX) inhibition of prostaglandin synthesis [2]. More of, in the cell bio assay COX enzyme especially COX-2 enzyme catalyzes the inflammatory mediator prostaglandin synthesis, prostacyclin and thromboxane as a consequence, suppression of COX-2 enzyme activity could be of therapeutic usage [3], [4]. In vivo selective COX-2 inhibition strategy of Ketorolac drugs is well known for cancer treatments due to their structural diversity, high efficacy, low side effect over other NSAIDs drugs $[4,5]$. Apart from that, Ketorolac salt also has selective inhibition of DDX3 protein through intra and intermolecular H-bond formation in the diagnosis of several types of cancer [6].

By rational investigation and functionalization of NSAIDs drugs, researchers put forward their studies on more potential action with reduced side effect and multiple diseases such as cancer HIV, neuro-degenerative diseases $[7,8]$. In this research we scrutinized computationally various derivatives of Ketorolac and their mode of action with amino acids of respected protein in view of their structural properties and future implementation on drug discovery. NSAIDs drugs have some adverse effects depending on the type and nature of unusual physical condition of the body and on the limit of dose [9]. Recently, it has been seen the trait of modifying drugs using halogens and alkyl group play important role in improving drug performance. Drug modification is another alternative way to search better agent, which can increase the selective action of drug and reduce the side effect [10]. Herein, we report the optimization of some Ketorolac derivatives to investigate their biochemical behaviour on the basis of quantum mechanical approach.

The free energy, electronic energy, enthalpy, dipole moment, electrostatic potential, HOMO-LUMO gap, hardness, softness, and chemical potential have been calculated. Molecular docking and nonbonding calculation have been performed to understand the 
binding affinity, mode(s) and interaction between drugs and the amino acid residues of human prostaglandin synthase protein (5F19). All the derivatives show better thermal stability, and chemical reactivity and few of the derivatives have better binding affinity, nonbonding interactions. From the regarding quantum chemical studies, we are assuming that, some of the designed compounds may have profound effect as drug.

\section{Methods and Materials}

\section{Computational Details}

In computer aided drug design, quantum mechanical methods are widely used to predict thermal, molecular orbital, and molecular electrostatic potential properties [11]. Initial geometry of Ketorolac (K) was taken from the online structure database named Chem Spider [12]. Geometry optimization and further modification of all structures carried out using Gaussian 09 program [13]. Density functional theory (DFT) with Becke's (B) [14] three-parameter hybrid model, Lee, Yang and Parr's (LYP) correlation functional [15] under Pople's 6-31g (d,p) basis set has been employed to optimize and elucidate their thermal and molecular orbital properties [16]. Initial optimization of all compounds was performed in the gas phase. Dipole moment, electronic energy, enthalpy, free energy, electrostatic potential and atomic partial charge are calculated for all the compounds.

Frontier molecular orbital features HOMO (highest occupied molecular orbital), LUMO (lowest unoccupied molecular orbital) were calculated at the same level of theory. For each of the drugs, HOMO-LUMO energy gap, hardness ( $\eta$ ), softness (S), and chemical potential were calculated from the energies of frontier HOMO and LUMO as reported considering Parr and Pearson interpretation $[17,18]$ of DFT and Koopmans theorem [19] on the correlation of ionization potential (I) and electron affinities (E) with HOMO and LUMO energy $(\varepsilon)$. The following equations are used to calculate hardness $(\eta)$, softness $(S)$, and chemical potential $(\mu)$;

$$
\operatorname{Gap}(\Delta E)=\eta=\frac{[\varepsilon L U M O-\varepsilon H O M O]}{2} ; \mu=\frac{[\varepsilon L U M O+\varepsilon H O M O]}{2} ; S=\frac{1}{\eta}
$$

\section{Molecular Docking and Nonbonding Interactions}

Molecular docking simulation was performed to understand the mechanism of the prostaglandin $\mathrm{H} 2$ ( $\mathrm{PGH} 2$ ) inhibition by newly designed Ketorolac analogues and their binding affinity and mode(s) with target protein [20]. The 3D structure of aspirin acetylated human cyclooxygenase-2 (PDB ID: 5F19) was obtained in pdb format from online protein data bank (PDB) database [21]. All hetero atoms and water molecules were eliminated using PyMol (version 1.3) software packages [22]. Energy minimization of the protein implemented by Swiss-Pdb viewer software (version 4.1.0)

[23]. Than optimized drugs were subjected for molecular docking study against human prostaglandin synthase protein (5F19). Finally, molecular docking simulation was performed by PyRx software (version 0.8) [24] considering the protein as macromolecule and the drug as ligand. In this analysis, rigid docking was performed where, all rotatable bonds were converted into non-rotatable with the center grid box size 20.8612, 37.5501 and 59.3402 A along x, y and $\mathrm{z}$ directions respectively. After docking, both the protein and ligand structures were saved in .pdbqt format required by Accelrys Discovery Studio (version 4.1) to analyze and visualize the docking result and search the interactions between ligands and target protein [25].

\section{ADMET Predictions}

In drug discovery, computational predictions are using to explore absorption, distribution, metabolism, excretion, and toxicity (ADMET) which saves on time and investment. AdmetSAR online database was utilized to predict ADMET properties of Ketorolac and its analogues [26].

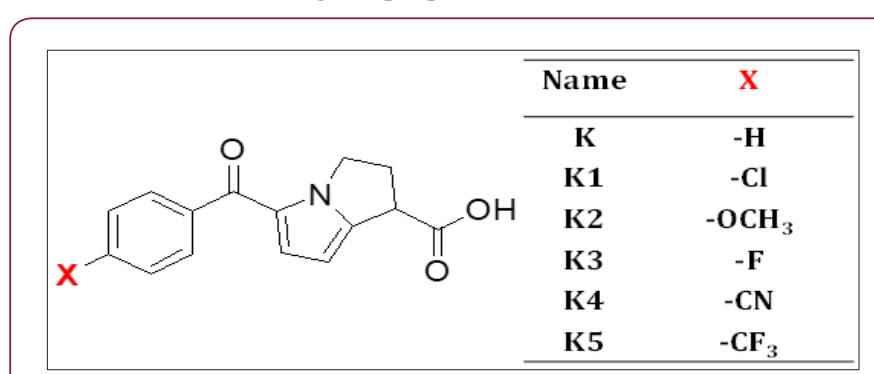

Figure 1: Chemical structure of Ketorolac (K) and its designed analogues.

\section{Result and Discussion}

\section{Thermochemical Analysis}

Simple modifications of molecular structure significantly influence the structural properties including thermal and molecular orbital parameters. From the free energy, and enthalpy values, spontaneity of a reaction and stability of a product can be predict [27]. In drug design, hydrogen bond formation and nonbonded interactions also influenced by dipole moment. Increased dipole moment can improve the binding property [28]. From thermodynamic data (Table 1), the free energy of Ketorolac is -859.6743 Hartree, where K1 shows the highest negative value (-1319.2329 Hartree). The $-\mathrm{Cl}$ substitution (K1) influence the free energy significantly. Highly negative free energy suggesting stable the configuration. Again, the dipole moment of Ketorolac is 0.5665 Debye where K4 shows the maximum dipole moment (5.2017 Debye) due to substitution of -CN group (Figure 1).

Table 1: The stoichiometry, molecular weight, electronic energy, enthalpy, free energy in Hartree and dipole moment (Debye) of Ketorolac $(\mathrm{K})$ and its derivatives.

\begin{tabular}{|c|c|c|c|c|c|c|}
\hline Name & Stoichiometry & Molecular weight & Electronic energy & Enthalpy & Free energy & Dipole moment \\
\hline $\mathrm{K}$ & $\mathrm{C}_{15} \mathrm{H}_{13} \mathrm{NO}_{3}$ & 255.26 & -859.6287 & -859.6122 & -859.6743 & 0.5665 \\
\hline $\mathrm{K} 1$ & $\mathrm{C}_{15} \mathrm{H}_{12} \mathrm{ClNO}_{3}$ & 289.71 & -1319.2329 & -1319.2151 & -1319.2807 & 2.0973 \\
\hline $\mathrm{K} 2$ & $\mathrm{C}_{16} \mathrm{H}_{15} \mathrm{NO}_{4}$ & 285.29 & -974.1228 & -974.1036 & -974.1718 & 1.6985 \\
\hline
\end{tabular}

Cite this article: Moniruzzaman, Mohammed JH, Mohammad NU, Amrin A, Tareq M.Quantum Chemical, Molecular Docking, and ADMET Predictions of Ketorolac and its Modified Analogues. Biomed J Sci \& Tech Res 11(5)-2018. BJSTR. MS.ID.002151. D0I: 10.26717/ BJSTR.2018.11.002151. 


\begin{tabular}{|l|l|l|l|l|l|l|}
\hline $\mathrm{K} 3$ & $\mathrm{C}_{15} \mathrm{H}_{12} \mathrm{FNO}_{3}$ & 273.25 & -958.8692 & -958.8518 & -958.9161 & 1.4239 \\
\hline $\mathrm{K} 4$ & $\mathrm{C}_{16} \mathrm{H}_{12} \mathrm{~N}_{3}$ & 280.27 & -951.8711 & -951.8527 & -951.9194 & 5.2017 \\
\hline $\mathrm{K} 5$ & $\mathrm{C}_{16} \mathrm{H}_{12} \mathrm{~F}_{3}$ & 323.27 & -1196.659 & -1196.6391 & -1196.7113 & 3.0639 \\
\hline
\end{tabular}

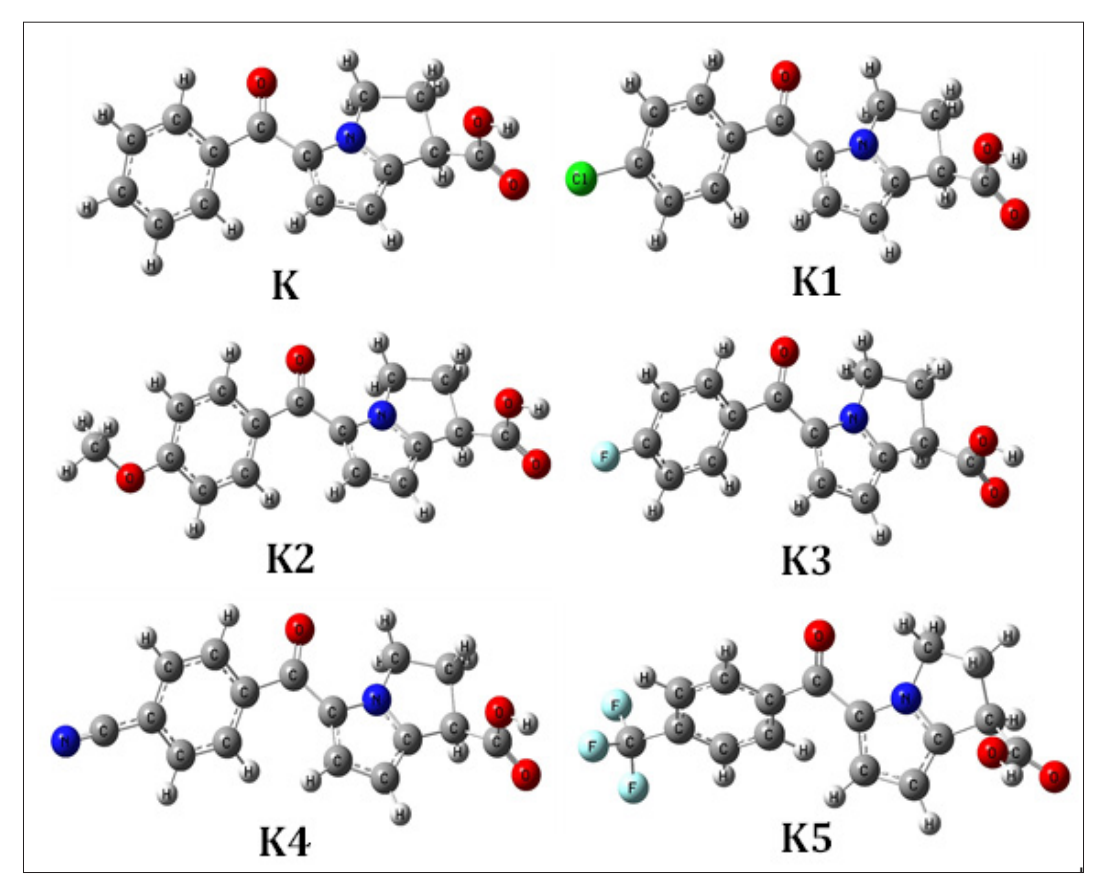

Figure 2: Most stable optimized structures of Ketorolac and newly designed drugs by analogues. Optimized with B3LYP/6$31 \mathrm{~g}(\mathrm{~d}, \mathrm{p})$ level theory.

\section{Molecular Orbital Properties}

The HOMO-LUMO energies, hardness, softness, chemical potential of all drugs are presented in Table 2. The electronic absorption relates to the transition from the ground to the first excited state and mainly described by one electron excitation from HOMO to LUMO [29]. The chemical hardness, softness, and chemical potential values depend on the energy of HOMO-LUMO
[8,30]. Kinetic stability increase with the increase of HOMO-LUMO gap. As a result, removal of electrons from ground state HOMO to excited state LUMO requires more energy. In our studies, Ketorolac shows the HOMO-LUMO gap $5.1935 \mathrm{eV}$, where K4 have lowest energy gap (4.1334 eV) and chemical potential $(-7.4028 \mathrm{eV})$ with highest softness $(0.4838 \mathrm{eV})$ which may contribute higher chemical reactivity (Figure 3 ).

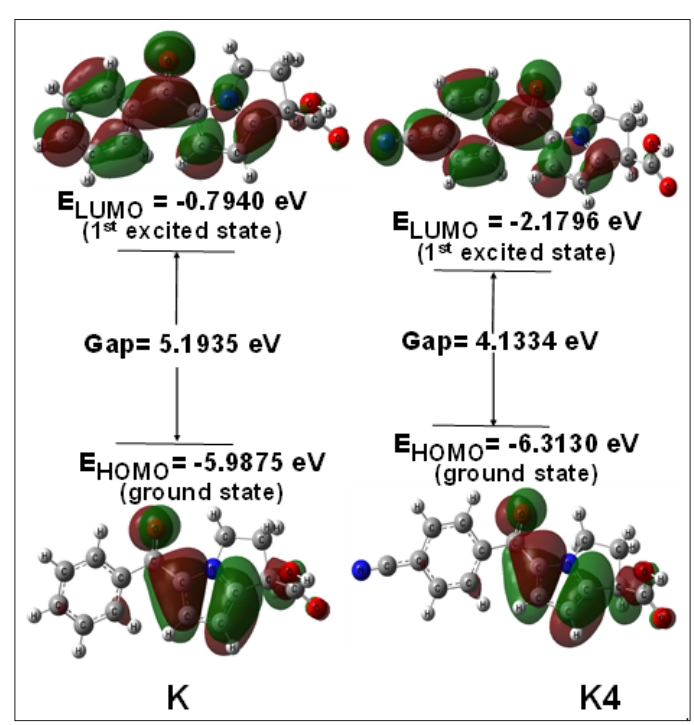

Figure 3: Frontier molecular orbital (HOMO-LUMO) and related transition energy of Ketorolac (K) and K4. 
Table 2: Energy (eV) of HOMO, LUMO, gap, hardness, softness and chemical potential of the designed drugs.

\begin{tabular}{|c|c|c|c|c|c|c|}
\hline Name & eHOMO & eLUMO & Gap & Hardness & Softness & Chemical potential \\
\hline K & -5.9875 & -0.7940 & 5.1935 & 2.5967 & 0.3851 & -3.3907 \\
\hline K1 & -6.1247 & -1.6868 & 4.4379 & 2.2189 & 0.4506 & -3.9057 \\
\hline K2 & -5.8586 & -1.2990 & 4.5596 & 2.2798 & 0.4386 & -3.5788 \\
\hline K3 & -6.0559 & -1.5347 & 4.5212 & 2.2606 & 0.4423 & -3.7953 \\
\hline K4 & -6.3130 & -2.1796 & 4.1334 & 2.0667 & 0.4838 & -7.4028 \\
\hline K5 & -6.1987 & -1.8471 & 4.3516 & 2.1758 & 0.4596 & -4.0229 \\
\hline
\end{tabular}

\section{Molecular Electrostatic Potential Analysis}

Molecular electrostatic potential (MEP) was calculated at B3LYP/6-31G (d) level of theory to forecast the reactive sites for electrophilic and nucleophilic attack of all optimized structures [31]. Red colour represent maximum negative area which favourable site for electrophilic attack, blue colour indicate the maximum positive area which favourable site for nucleophilic attack and green colour represent zero potential area. MEP displays molecular size, shape as well as positive, negative and neutral electrostatic potential regions simultaneously in terms of colour grading. It is seen from MEP map, region having the negative potential are over electronegative atom (oxygen atoms) and having positive potential are over hydrogen atoms. Here, the maximum positive potentiality is found for Ketorolac is -0.2475 a.u (deepest red) for oxygen atoms and the highest positive potentiality of K5 is +0.1837 a.u (deepest blue) of hydrogen atoms (Figure 4)

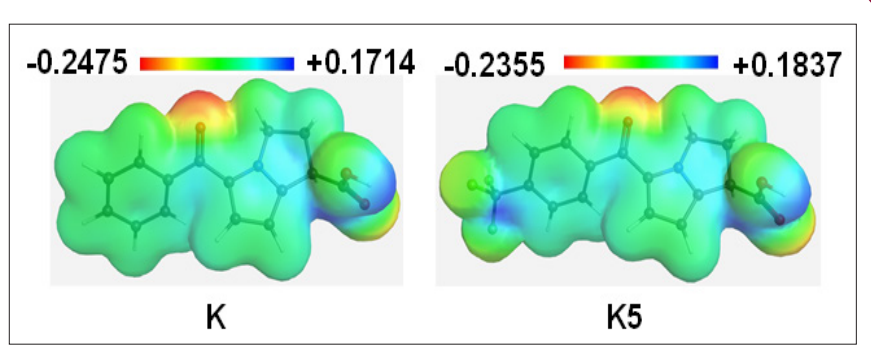

Figure 4: Molecular electrostatic potential maps of Ketorolac (K) and K5.

\section{Molecular Docking and Nonbonding Interactions Analysis}

Binding affinities and ligand-protein interactions are summarized in Table 3. Greater negative values of binding affinity indicate stronger binding between drugs and the receptor protein. Strong hydrogen bonding is the most significant contributing factor in increasing binding affinity of drugs with the receptor (Figure
5). Non-covalent interactions such as hydrogen bond, halogen bond and hydrophobic interaction are involved in the binding of examined drugs. Recently, it is reported that, hydrogen bond of $<2.3$ $\AA$ are able to increase the binding affinity by several magnitude [32] and halogen bonds have almost similar importance as hydrogen bond in chemical and biological system [33]. The binding affinity of Ketorolac is $-8.7 \mathrm{kcal} / \mathrm{mol}$ where, $\mathrm{K} 2, \mathrm{~K} 4$ and $\mathrm{K} 5$ have considerably increased to $-10.0,-9.5$ and $-9.1 \mathrm{kcal} / \mathrm{mol}$ respectively. Decreased binding affinities are found in case of $\mathrm{K} 1$ (-8.6 kcal/mol) and K3 (-8.5 kcal/mol). Significant hydrogen and halogen bonding observed in K5 (Figure 6), which not only contributes in increasing binding affinity but also increase binding speciality.

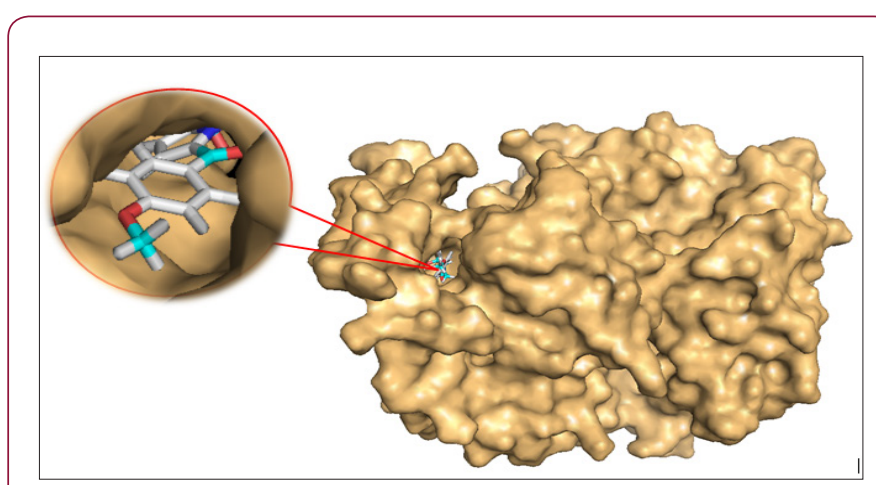

Figure 5: Docked conformation of $\mathrm{K} 2$ at inhibition bounding site of receptor protein (5F19).

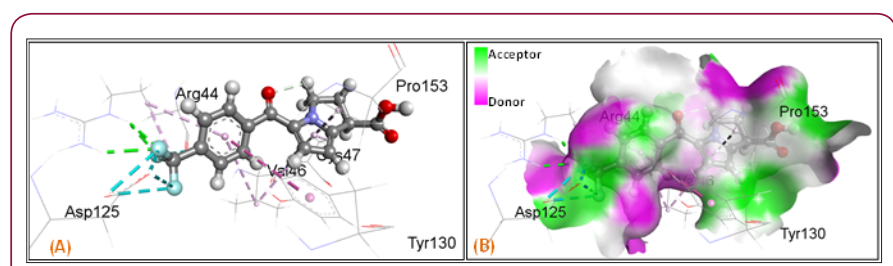

Figure 6: (A) Nonbonding interactions of $\mathrm{K} 5$ with receptor protein 5F19. (B) Hydrogen bond surface of 5F19 with K5.

Table 3: Binding affinity and nonbonding interactions of Ketorolac $(\mathrm{K})$ and its modified derivatives.

\begin{tabular}{|c|c|c|c|c|}
\hline Name & Binding affinity (kcal/mol) & Residues in contact & Interaction types & Distance (Å) \\
\hline \multirow{5}{*}{$\mathrm{K}$} & \multirow{5}{*}{-8.7} & Asp157 & PA & 3.38832 \\
\hline & & Gly135 & Ps & 2.64184 \\
\hline & & Val155 & Aps & 5.01994 \\
\hline & & Pro154 & Pal & 4.70537 \\
\hline & & Pro156 & Pal & 4.04921 \\
\hline
\end{tabular}

Cite this article: Moniruzzaman, Mohammed JH, Mohammad NU, Amrin A, Tareq M.Quantum Chemical, Molecular Docking, and ADMET Predictions of Ketorolac and its Modified Analogues. Biomed J Sci \& Tech Res 11(5)-2018. BJSTR. MS.ID.002151. DOI: 10.26717/ 


\begin{tabular}{|c|c|c|c|c|}
\hline \multirow{8}{*}{ K1 } & \multirow{8}{*}{-8.6} & Asn34 & $\mathrm{H}$ & 2.40192 \\
\hline & & Cys47 & $\mathrm{H}$ & 1.94084 \\
\hline & & Cys47 & C & 3.1608 \\
\hline & & Leu152 & A & 5.15481 \\
\hline & & Asn34 & $\mathrm{H}$ & 2.40192 \\
\hline & & Cys47 & $\mathrm{H}$ & 1.94084 \\
\hline & & Cys47 & $\mathrm{C}$ & 3.1608 \\
\hline & & Leu152 & A & 5.15481 \\
\hline \multirow{7}{*}{ K2 } & \multirow{7}{*}{-10.0} & Asn43 & $\mathrm{H}$ & 2.62371 \\
\hline & & Arg44 & $\mathrm{H}$ & 2.34991 \\
\hline & & Gln 461 & $\mathrm{H}$ & 2.33115 \\
\hline & & Gln 461 & $\mathrm{H}$ & 3.70579 \\
\hline & & Cys47 & Pal & 4.64343 \\
\hline & & Pro153 & Pal & 4.27612 \\
\hline & & Leu152 & Pal & 5.46447 \\
\hline \multirow{11}{*}{ K3 } & \multirow{11}{*}{-8.5} & Asp125 & $\mathrm{H}$ & 2.32267 \\
\hline & & Ala151 & $\mathrm{H}$ & 2.86298 \\
\hline & & His39 & $\mathrm{H}$ & 3.38968 \\
\hline & & $\operatorname{Arg} 44$ & $\mathrm{H}$ & 1.73807 \\
\hline & & $\operatorname{Arg} 44$ & $\mathrm{H}$ & 2.66653 \\
\hline & & Tyr130 & $\mathrm{C}$ & 2.66002 \\
\hline & & His39 & $\mathrm{C}$ & 3.07968 \\
\hline & & Pro40 & $\mathrm{X}$ & 3.73344 \\
\hline & & Cys46 & Pal & 2.42417 \\
\hline & & Cys47 & Pal & 3.25373 \\
\hline & & Pro153 & Pal & 4.95221 \\
\hline \multirow{6}{*}{ K4 } & \multirow{6}{*}{-9.5} & Phe529 & PA & 4.37944 \\
\hline & & Phe381 & Ppt & 5.1648 \\
\hline & & Leu534 & Pal & 4.60338 \\
\hline & & Val349 & Pal & 4.44982 \\
\hline & & Ala527 & Pal & 4.69393 \\
\hline & & Leu531 & Pal & 5.28223 \\
\hline \multirow{13}{*}{ K5 } & \multirow{13}{*}{-9.1} & Arg44 & $\mathrm{H}$ & 2.38051 \\
\hline & & $\operatorname{Arg} 44$ & $\mathrm{H}$ & 2.23812 \\
\hline & & $\operatorname{Arg} 44$ & $\mathrm{H}$ & 2.38811 \\
\hline & & $\operatorname{Arg} 44$ & $\mathrm{X}$ & 2.93073 \\
\hline & & Asp125 & $\mathrm{X}$ & 3.10573 \\
\hline & & Try130 & Ppt & 5.78627 \\
\hline & & Asp125 & $\mathrm{X}$ & 2.69996 \\
\hline & & Asp125 & $\mathrm{X}$ & 3.64315 \\
\hline & & Cys47 & Pal & 3.13359 \\
\hline & & $\operatorname{Arg} 44$ & A & 4.07073 \\
\hline & & Arg44 & Pal & 4.79261 \\
\hline & & Val46 & Pal & 5.19041 \\
\hline & & Pro153 & Pal & 3.82592 \\
\hline
\end{tabular}

Here, $\mathrm{H}=$ Conventional hydrogen bond, $\mathrm{C}=$ Carbon hydrogen bond, $\mathrm{A}=\mathrm{Alkyl}$, Aps= Amide-pi stacked, $\mathrm{PA}=\mathrm{Pi}-\mathrm{anion}, \mathrm{PS}=\mathrm{Pi}-\mathrm{sigma}$, Pal= Pi-alkyl, PPS $=$ Pi-pi stacked, Ppt= Pi-Pi T shaped, $X=$ Halogen bond 
Nonbonding interactions are important consideration of drug protein conjugation. Except conventional H-bond frequently observed non-bonding interactions are $\mathrm{CH} / \pi, \mathrm{OH} / \pi$, and $\mathrm{CH} / \mathrm{O}$. Upon introduction of $-\mathrm{Cl}$ group in $\mathrm{K} 1$ structure conventional H-bond predominated with both Cysteine and Asparagin moiety within closer distance which is very reasonable since of chlorine contribution to total conjugation. On the other hand, methoxy group promoted several $\mathrm{H}$-bonds through structural similar amino acids such as Asparagin, Glutamine, and Ariginine also in this case $\mathrm{CH} / \pi$ observed with Cystein, Proline and Leucine part of the protein. A variety of binding sites including both conventional and non-conventional $\mathrm{H}$-bonds observed upon fluorine substitution, in where Arginine, Aspartic acid positioned most favorable distance toward the drug. Apart from that, $\mathrm{CH} / \pi$ interactions observed for Cystein, Tyrosine and Proline. No such contribution of conventional H-bonds observed during -CN group substitution rather than $\pi /$ alkyl non-bonding interactions observed with multiple amino acids. Lastly, in the K5, short distance halogen bonds observed with Aspartic acid. Another important Pi-Pi T shaped (Ppt) interaction observed in K4 and K5.

\section{ADMET Predictions}

ADMET calculation has performed to investigate the safety level of designed analogues after administration in the human body. According to Admet SAR data (Table 4), Ketorolac shows II category acute oral toxicity and rest of the analogues show III category acute oral toxicity, which suggesting less toxicity of analogues than parent drug. All the analogues are non-carcinogenic, show positive response for blood brain barrier (BBB) and human intestinal absorption criteria. All drugs are P-glycoprotein non-inhibitor where, P-glycoprotein inhibition can interrupt the absorption, permeability and retention of the drugs [34]. However, all the compounds show weak inhibitory feature for human ether-a-gogo-related gene (hERG) which can lead to long QT syndrome [35], so furthermore study of this aspect is necessary.

Table 4: Selected pharmacokinetic parameters of Ketorolac and its designed derivatives.

\begin{tabular}{|c|c|c|c|c|c|c|}
\hline Name & Blood brain barrier & Human intestinal absorption & P-glycoprotein inhibitor & hERG & Carcinogen & Acute oral toxicity \\
\hline $\mathrm{K}$ & $+(0.7918)$ & $+(0.9919)$ & $\mathrm{NI}(0.8684)$ & $\mathrm{WI}(0.9478)$ & $\mathrm{NC}(0.9592)$ & $\mathrm{II}(0.4567)$ \\
\hline $\mathrm{K} 1$ & $+(0.7849)$ & $+(0.9932)$ & $\mathrm{NI}(0.8430)$ & $\mathrm{WI}(0.9318)$ & $\mathrm{NC}(0.9351)$ & $\mathrm{III}(0.5264)$ \\
\hline $\mathrm{K} 2$ & $+(0.7284)$ & $+(0.9603)$ & $\mathrm{NI}(0.8523)$ & $\mathrm{WI}(0.9110)$ & $\mathrm{NC}(0.9744)$ & $\mathrm{III}(0.5876)$ \\
\hline $\mathrm{K} 3$ & $+(0.8257)$ & $+(0.9931)$ & $\mathrm{NI}(0.8558)$ & $\mathrm{WI}(0.9572)$ & $\mathrm{NC}(0.9432)$ & $\mathrm{III}(0.5493)$ \\
\hline $\mathrm{K} 4$ & $+(0.7407)$ & $+(0.9806)$ & $\mathrm{NI}(0.7115)$ & $\mathrm{WI}(0.9571)$ & $\mathrm{NC}(0.9564)$ & $\mathrm{III}(0.4682)$ \\
\hline $\mathrm{K} 5$ & $+(0.8653)$ & $+(1.0000)$ & $\mathrm{NI}(0.7299)$ & $\mathrm{WI}(0.9767)$ & $\mathrm{NC}(0.9373)$ & $\mathrm{III}(0.5252)$ \\
\hline
\end{tabular}

Here, $N I=$ Non inhibitor, $W I=$ Weak inhibitor, $N C=$ Non carcinogenic

\section{Conclusion}

From quantum chemical calculations, all the analogues are thermally and configurationally more stable than Ketorolac. Also have smaller HOMO-LUMO gap and higher chemical reactivity than parent drug. From docking simulation, K2, K4, and K5 show higher binding affinity than $\mathrm{K}$, where most significant interactions are observed for K5-5F19 complex. ADMET results predict that, analogues are non-carcinogenic, and relatively less harmful for oral administration. Considering above investigation, $\mathrm{K} 2$, $\mathrm{K} 4$, and $\mathrm{K} 5$ can be potent new possible candidate for the better performance.

\section{Acknowledgement}

Authors are thankful to Mohammad A. Halim, COE, The Red Green Research Centre, Dhaka, Bangladesh for support during optimization.

\section{References}

1. Schneider G, Fechner U (2005) Computer-based de novo design of druglike molecules. Nature Reviews Drug Discovery 4(8): 649-663.

2. Mallinson TE (2017) A review of ketorolac as a prehospital analgesic. Journal of Paramedic Practice 9(12): 522-526.
3. Wiseman LR, McTavish D (1993) Formestane. A review of its pharmacodynamic and pharmacokinetic properties and therapeutic potential in the management of breast cancer and prostatic cancer. Drugs 45(1): 66-84.

4. Bandgar BP, Adsul LK, Chavan HV, Jalde SS, Shringare SN, et al. (2012) Synthesis, biological evaluation, and docking studies of 3-(substituted)aryl-5-(9-methyl-3-carbazole)-1H-2-pyrazolines as potent antiinflammatory and antioxidant agents. Bioorganic \& medicinal chemistry letters 22(18): 5839-5844.

5. Kato M, Nishida S, Kitasato H, Sakata N, Kawai S (2001) Cyclooxygenase-1 and cyclooxygenase-2 selectivity of non-steroidal anti-inflammatory drugs: investigation using human peripheral monocytes. Journal of Pharmacy and Pharmacology 53(12): 1679-1685.

6. Bheemanapally K, Thimmaraju MK, Kasagoni S, Prathyusha Thatikonda Swathi Akula, et al. (2017) In vitro anti-cancer activity of rosuvastatin and ketorolac nanoformulations against DDX3. Journal of Young Pharmacists 9(4): 537-544.

7. Uzzaman M, Hoque MJ (2018) Physiochemical, molecular docking, and pharmacokinetic studies of Naproxen and its modified derivatives based on DFT. International Journal of Scientific Research and Management 6(9): 12-19.

8. Azam F, Alabdullah NH, Ehmedat HM, Abulifa AR, Taban I, et al. (2017) NSAIDs as potential treatment option for preventing amyloid $\beta$ toxicity 
in Alzheimer's disease: an investigation by docking, molecular dynamics, and DFT studies. Journal of Biomolecular Structure and Dynamics 36(8): 2099-2117.

9. Vonkeman HE, Van de Laar MAFJ (2010) Nonsteroidal anti-inflammatory drugs: adverse effects and their prevention. In: Seminars in arthritis and rheumatism. Elsevier 39(4): 294-312.

10. Juillerat-Jeanneret L, Schmitt F (2007) Chemical modification of therapeutic drugs or drug vector systems to achieve targeted therapy: looking for the grail. Medicinal research reviews 27(4): 574-590.

11. Gleeson MP, Gleeson D (2009) QM/MM Calculations in Drug Discovery: A Useful Method for Studying Binding Phenomena? Journal of Chemical Information and Modeling 49(3): 670-677.

12. Pence HE, Williams A (2010) Chem Spider: An Online Chemical Information Resource. Journal of Chemical Education 87(11): 11231124.

13. MJ Frisch, GW Trucks, HB Schlegel, GE Scuseria, MA Robb, et al. (2009) Gaussian09 RA, Gaussian. Inc, Wallingford CT.

14. Becke AD (1988) Density-functional exchange-energy approximation with correct asymptotic behavior. Phys Rev A 38: 3098-3100.

15. Lee C, Yang W, Parr RG (1988) Development of the Colle-Salvetti correlation-energy formula into a functional of the electron density Phys Rev B 37: 785-789.

16. Kruse H, Goerigk L, Grimme S (2012) Why the Standard B3LYP/6-31G* Model Chemistry Should Not Be Used in DFT Calculations of Molecular Thermochemistry: Understanding and Correcting the Problem. The Journal of Organic Chemistry 77(23): 10824-10834.

17. Calais JL (1993) Density-functional theory of atoms and molecules. RG Parr and W Yang, Oxford University Press, New York, Oxford, 1989. IX + 333 pp. Price $£ 45.00$. International Journal of Quantum Chemistry 47(1): 101.

18. Pearson RG (1995) The HSAB Principle - more quantitative aspects. Inorganica Chimica Acta 240(1-2): 93-98.

19. Pearson RG (1986) Absolute electronegativity and hardness correlated with molecular orbital theory. Proceedings of the National Academy of Sciences 83(22): 8440-8441.

20. Seeliger D, De Groot BL (2010) Conformational transitions upon ligand binding: holo-structure prediction from apo conformations. PLoS computational biology 6: e1000634.

21. Lucido MJ, Orlando BJ, Vecchio AJ, Malkowski MG (2016) Crystal Structure of Aspirin-Acetylated Human Cyclooxygenase-2: Insight into the Formation of Products with Reversed Stereochemistry. Biochemistry 55(8): 1226-1238.

22. DELANO WL (2002) The PyMOL Molecular Graphics System. De-Lano Scientific, San Carlos, CA, USA.

23. Guex N, Peitsch MC (1997) SWISS-MODEL and the Swiss-Pdb Viewer: An environment for comparative protein modeling. ELECTROPHORESIS 18(15): 2714-2723.

24. Dallakyan S, Olson AJ (2015) Small-Molecule Library Screening by Docking with PyRx. In: Hempel JE, Williams CH, Hong CC (eds). Chemical Biology: Methods and Protocols. Springer New York, New York, NY, pp 243-250.

25. Version ADS (2017) 4.0, Accelrys, San Diego, USA.

26. Cheng F, Li W, Zhou Y, Shen J, Wu Z, et al. (2012) admet SAR: A Comprehensive Source and Free Tool for Assessment of Chemical ADMET Properties. Journal of Chemical Information and Modeling 52(11): 3099-3105.

27. Cohen N, Benson SW (1993) Estimation of heats of formation of organic compounds by additivity methods. Chemical Reviews 93(7): 2419-2438.

28. Lien EJ, Guo ZR, Li RL, Su CT (1982) Use of dipole moment as a parameter in drug-receptor interaction and quantitative structure-activity relationship studies. Journal of Pharmaceutical Sciences 71(6): 641-655.

29. Saravanan S, Balachandran V (2014) Quantum chemical studies, natural bond orbital analysis and thermodynamic function of 2 , 5-dichlorophenylisocyanate. Spectrochimica Acta Part A: Molecular and Biomolecular Spectroscopy 120: 351-364.

30. Parr RG, Zhou Z (1993) Absolute hardness: unifying concept for identifying shells and subshells in nuclei, atoms, molecules, and metallic clusters. Accounts of Chemical Research 26: 256-258.

31. Politzer P, Murray JS (1991) Molecular electrostatic potentials and chemical reactivity. Reviews in computational chemistry 273-312.

32. Wade RC, Goodford PJ (1989) The role of hydrogen-bonds in drug binding. Progress in clinical and biological research 289: 433-444.

33. Sarwar MG, Ajami D, Theodorakopoulos G, Petsalakis ID, Rebek J Jr (2013) Amplified halogen bonding in a small space. Journal of the American Chemical Society 135: 13672-13675.

34. Amin ML (2013) P-glycoprotein inhibition for optimal drug delivery. Drug Target Insights 7: 27-34.

35. Sanguinetti MC, Tristani Firouzi M (2006) hERG potassium channels and cardiac arrhythmia. Nature 440(7083): 463-469.
ISSN: 2574-1241

DOI: 10.26717/BJSTR.2018.11.002151

Moniruzzaman. Biomed J Sci \& Tech Res

This work is licensed under Creative

Commons Attribution 4.0 License

Submission Link: https://biomedres.us/submit-manuscript.php

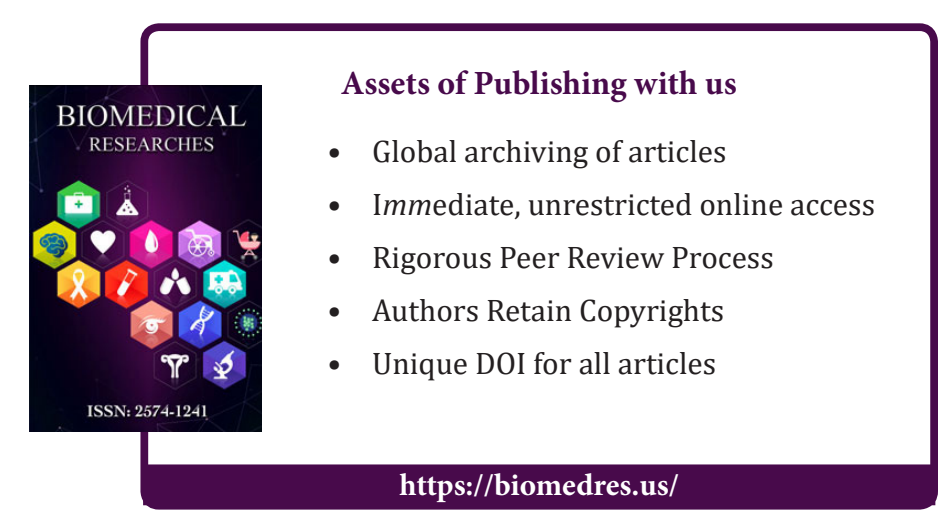

